\title{
miR-221 stimulates breast cancer cells and cancer-associated fibroblasts (CAFs) through selective interference with the A20/c-Rel/CTGF signaling
}

Maria Francesca Santolla ${ }^{1}$, Rosamaria Lappano ${ }^{1}$, Francesca Cirillo ${ }^{1}$, Damiano Cosimo Rigiracciolo ${ }^{1}$, Anna Sebastiani ${ }^{1}$, Sergio Abonante ${ }^{2}$, Pierfrancesco Tassone ${ }^{3}$, Pierosandro Tagliaferri ${ }^{3}$, Maria Teresa Di Martino ${ }^{3 *}$,

Marcello Maggiolini ${ }^{*}$ and Adele Vivacqua ${ }^{1}$

\begin{abstract}
Background: MicroRNA (miRNAs) are non-coding small RNA molecules that regulate gene expression by inhibiting the translation of target mRNAs. Among several dysregulated miRNAs in human cancer, the up-regulation of miR-221 has been associated with development of a variety of hematologic and solid malignancies. In this study, we investigated the involvement of miR-221 in breast cancer.
\end{abstract}

Methods: TaqMan microRNA assay was used to detect the miR-221 levels in normal cells and in MDA-MB 231 and SkBr3 breast cancer cells as well as in main players of the tumor microenvironment, namely cancer-associated fibroblasts (CAFs). miR-221 mimic sequence and locked nucleic acid (LNA)-i-miR-221 construct were used to induce or inhibit, respectively, the miR-221 expression in cells used. Quantitative PCR and western blotting analysis were performed to evaluate the levels of the miR-221 target gene A20 (TNFAIP3), as well as the member of the NF-kB complex namely c-Rel and the connective tissue growth factor (CTGF). Chromatin immunoprecipitation (ChIP) assay was performed to ascertain the recruitment of c-Rel to the CTFG promoter. Finally, the cell growth and migration in the presence of LNA-i-miR-221 or silencing c-Rel and CTGF by specific short hairpin were assessed by cell count, colony formation and boyden chambers assays. Statistical analysis was performed by ANOVA.

Results: We first demonstrated that LNA-i-miR-221 inhibits both endogenous and ectopic expression of miR-221 in our experimental models. Next, we found that the A20 down-regulation, as well as the up-regulation of c-Rel induced by miR-221 were no longer evident using LNA-i-miR-221. Moreover, we established that the miR-221 dependent recruitment of c-Rel to the NF-kB binding site located within the CTGF promoter region is prevented by using LNA-i-miR-221.

Furthermore, we determined that the up-regulation of CTGF mRNA and protein levels by miR-221 is no longer evident using LNA-i-miR221 and silencing c-Rel. Finally, we assessed that cell growth and migration induced by miR-221 in MDAMB 231 and SkBr3 breast cancer cells as well as in CAFs are abolished by LNAi-miR-221 and silencing c-Rel or CTGF.

Conclusions: Overall, these data provide novel insights into the stimulatory action of miR-221 in breast cancer cells and CAFs, suggesting that its inhibition may be considered toward targeted therapeutic approaches in breast cancer patients.

Keywords: Breast cancer, CAFs, miR-221, A20, C-Rel, CTGF

\footnotetext{
* Correspondence: teresadm@unicz.it; marcellomaggiolini@yahoo.it; marcello.maggiolini@unical.it

${ }^{3}$ Department of Experimental and Clinical Medicine, Magna Graecia University, Catanzaro, Italy

'Department of Pharmacy, Health and Nutritional Sciences, University of

Calabria, Rende, Italy

Full list of author information is available at the end of the article
}

(c) The Author(s). 2018 Open Access This article is distributed under the terms of the Creative Commons Attribution 4.0 International License (http://creativecommons.org/licenses/by/4.0/), which permits unrestricted use, distribution, and reproduction in any medium, provided you give appropriate credit to the original author(s) and the source, provide a link to the Creative Commons license, and indicate if changes were made. The Creative Commons Public Domain Dedication waiver (http://creativecommons.org/publicdomain/zero/1.0/) applies to the data made available in this article, unless otherwise stated. 


\section{Background}

microRNAs (miRNAs) are small non-coding RNA molecules (of $\sim 22$ nucleotides), which regulate the expression of up to $30 \%$ protein coding genes, usually binding to specific sites within the 3' untranslated regions (3'-UTRs) of the mRNA targets [1]. The expression of miRNAs is cell- and tissue-specific, indicating that miRNAs are closely associated with cell differentiation and development [2]. In addition, miRNAs exert a regulatory role in several pathophysiological processes, including many types of tumor [2-5]. In this regard, it should be mentioned that a distinct miRNA may be found up-regulated in certain carcinomas and downregulated in others, suggesting, therefore, a potential oncogenic and tumor suppressor function, respectively, depending on the cell context. Breast cancer, which represents the most common female malignancy in western countries [6], is one of the first solid tumors investigated for miRNA expression [7]. Among the most significant miRNAs overexpressed in breast carcinoma, miR-21 has been shown to mediate cell survival and invasion [7, 8]. Likewise, miR-144 was shown to induce stimulatory effects in breast cancer cells [9] and miR-103/miR-107 were associated with a poor outcome in patients affected by triple-negative breast cancer [10]. Next, the involvement of miR-221/miR-222 has been recently shown in many tumors [11]. For instance, miR-222 was implicated in the progression [12] and the drugresistance [13] of breast cancer, whereas miR-221 elicited stimulatory effects in diverse types of malignancies downregulating certain onco-suppressor genes [14, 15]. In addition, in bone marrow-derived macrophages, miR-221 was reported to down-regulate the expression of the ubiquitin-editing A20 [16] enzyme, which acts toward the maintenance of tissue homeostasis and the prevention of inflammatory disorders [17]. In this vein, it was demonstrated that A20 inhibits the activity of the nuclear factor kappa B (NF-kB) [18], which is largely involved in the development of many types of tumors $[19,20]$. A variety of mechanisms may regulate the expression of A20, like specific A20 binding proteins (ABINs), the ubiquitin binding protein TAX1BP1 and the histone methyltransferase Ash1l [21-23]. In addition, miR-29c, miR-873 and let-7 have been reported to suppress A20 expression, therefore contributing to the activation of NF-kB signaling [24-26]. miR-125a and miR$125 \mathrm{~b}$ were shown to also target A20 and aberrantly activate the NF-kB transduction pathway in B-cell lymphoma [27]. NF-kB embraces a family of transcription factors formed by hetero- or homo-dimers, including the subunits p65 (RelA) p50, p52, c-Rel or RelB [28]. The NF-kB inhibitor alpha (IkB) $\alpha$, one of the members of the IkB family, keeps the dimers in an inactive form within the cytoplasm. The release from the IkB $\alpha$ leads to nuclear translocation of the NF-kB dimers and their DNA binding, hence leading to the transcription of a variety of genes [28]. Recently, it has been reported that A20 may inhibit the NF-kB activity by reducing the nuclear levels of c-Rel [29]. c-Rel is a 587-amino acid protein, which contains a highly conserved N-terminal DNA-binding/dimerization domain named Rel homology domain (RHD) [30]. The C-terminal half of c-Rel encompasses two C-terminal transactivation sequences (TAD1 and TAD2), separated from the RHD by a transactivation inhibitory domain (RID) [30]. c-Rel exists either as a homodimer or a heterodimer with p50, however c-Rel can also form dimers with p65 and p52 [30]. Dysregulated expression and activity of c-Rel have been demonstrated in various cancers [30]. In agreement with these findings, the ectopic expression of c-Rel triggered the development of breast tumors in transgenic mice [31]. It has been recently reported that $\mathrm{NF}-\mathrm{kB}$ regulates the expression of the connective tissue growth factor (CTGF) [32, 33]. CTGF is involved in many cellular processes including cell adhesion, matrix production, structural remodelling, angiogenesis, cell proliferation and differentiation [34]. CTGF is mainly regulated by mechanical stresses as well as by a number of cytokines and growth factors [34]. Previous studies have reported its involvement in various malignancies as breast and endometrial tumors [35], melanoma [36], gastric [37], pancreatic [38], prostate [39], hepatic [40] and colon cancer [41].

On the basis of the aforementioned observations, we attempted to provide novel insights into the molecular mechanism through which miR-221 may induce oncogenic effects in breast tumor, using as experimental models crucial players of the tumor microenvironment as cancer-associated fibroblasts (CAFs) [42], the MDA-MB 231 and SkBr3 breast cancer cells. We found that miR-221 down-regulates A20 expression and increases both c-Rel and CTGF, leading to cell growth and migration. Worthy, these effects were abrogated silencing c-Rel and CTGF expression and using the specific Locked Nucleic Acid (LNA)-Inhibitor of miR-221 (LNA-i-miR-221), which is a 13-mer oligonucleotide designed specifically to sequester the miR-221 [43, 44]. In particular, the LNA-i-miR-221, recently approved for first-in-human clinical trial (EudraCT 201,700,261,533), takes advantage from both LNA technology and phosphorothioate backbone to increase the seed sequence binding and nuclease resistance in vivo, respectively $[45,46]$. Together, our data highlight the oncogenic action of miR-221 in CAFs and breast cancer cells, hence suggesting that its inhibition may represent a further preventive and therapeutic strategy in breast cancer.

\section{Methods}

\section{Bioinformatic tools}

The putative promoter sequences of CTGF $(-625 \mathrm{bp} /+$ $62 \mathrm{bp})$ and A20 3'-UTR were retrieved from the National Center for Biotechnology Information (NCBI) (http://www.ncbi.nlm.nih.gov). Prediction of transcription factors within CTGF promoter was performed using TransFac (http://www.generegulation.com) site and 
Promo 3.0.2 (http://alggen.lsi.upc.es/). miR-221 target genes were identified using miRNAbase (http://www. miRNAbase.org), Targetscan (http://www.targetscan.org) and miRDip (http://ophid.utoronto.ca/mirDIP/) sites.

\section{Cell cultures}

The breast cancer cell lines (triple-negative MDA-MB 231 and overexpressing epidermal growth factor receptor $2 \mathrm{SkBr} 3$ ) and non-malignant breast epithelial cell (MCF10A) were obtained from the ATCC (Manassas, USA). SkBr3 and MDA-MB 231 breast cancer cells were maintained, respectively, in RPMI-1640 without phenol red and DMEM/F12 media (Life Technologies, Milan, Italy) with a supplement of $10 \%$ fetal bovine serum (FBS) and $100 \mu \mathrm{g} / \mathrm{ml}$ of penicillin/streptomycin (Life Technologies, Milan, Italy). MCF10A cell line were cultured in DMEM/F12 media (Life Technologies, Milan, Italy) following the instruction of ATCC (Manassas, USA). All cell types were used less than 6 months after resuscitation and routinely tested and authenticated according to the ATCC suggestions. CAFs were extracted from invasive mammary ductal carcinomas obtained from mastectomies, while normal fibroblasts were isolated from a noncancerous breast tissue at least $2 \mathrm{~cm}$ from the outer tumor margin. Briefly, in both cases specimens were cut into smaller pieces (1-2 mm diameter), placed in digestion solution (400 IU collagenase I, 100 IU hyaluronidase, and $10 \%$ FBS, containing antibiotic and antimycotic solution) and incubated overnight at $37{ }^{\circ} \mathrm{C}$. The cells were then separated by differential centrifugation at $90 \times \mathrm{g}$ for $2 \mathrm{~min}$. Supernatant containing fibroblasts was centrifuged at $485 \times \mathrm{g}$ for $8 \mathrm{~min}$; the pellet obtained was suspended in fibroblasts growth medium (Medium 199 and Ham's F12 mixed 1:1 and supplemented with 10\% FBS) and cultured at $37{ }^{\circ} \mathrm{C}$ in $5 \% \mathrm{CO}_{2}$. Primary cells cultures of breast fibroblasts were characterized by immunofluorescence. Briefly cells were incubated with human anti-vimentin (V9, sc6260) and human anti-cytokeratin 14 (LL001 sc-53,253), both from Santa Cruz Biotechnology (DBA, Milan, Italy) (data not shown). To characterize fibroblasts activation, we used anti-fibroblast activated protein $\alpha$ (FAP $\alpha)$ antibody (SS-13, sc-100,528; Santa Cruz Biotechnology, DBA, Milan, Italy) (data not shown). Signed informed consent from all the patients was obtained and all samples were collected, identified and used in accordance with approval by the Institutional Ethical Committee Board (Regional Hospital, Cosenza, Italy). All cell lines were grown in a $37^{\circ} \mathrm{C}$ incubator with $5 \% \mathrm{CO}_{2}$.

\section{Plasmid and transfection}

The mimic miR-221 (miR-221) and negative control (miR-Ctrl) sequences were purchased from Ambion (Life Technologies, Milan, Italy). Custom LNA oligonucleotides were provided by Exiqon (Vedbaek, DenMark). LNA-i-
miR-221 is a 13-mer DNA/LNA oligonucleotide whose sequence is CAGACAATGTAGC, with a fully PS-modified backbone. It was purified by HPLC followed by $\mathrm{Na}+$ salt exchange and lyophilisation [45]. The CTGF luciferase reporter plasmid p(-1999/+36)-Luc (CTGF-luc), based on the backbone of vector pGL3-basic (Promega) [47], was a gift from Dr. B. Chaqour. c-Rel shRNA sequence (shRel) was obtained from TRC consortium (TRCN0000039986) and cloned, as described previously [48], in the piggyBac transposon vector (PB-H1-shRNA-GFP), kindly provided by Dr. W.T. Khaled, University of Cambridge, UK. The shRNA construct for CTGF, obtained from the Open Biosystems (www.Biocat.de), contains the clone ID TRCN0000061950 and is based on the lentiviral expression vector PLKO.1.

\section{RNA extraction and real time-PCR}

Cells were maintained in regular growth medium and then switched to medium lacking serum before the transfection with $25 \mathrm{nM}$ miR-Ctrl, miR-221, $100 \mathrm{nM}$ LNA-i-miR-221 and $5 \mu \mathrm{g}$ short hairpin plasmids, as indicated. Total RNA were extracted from cultured cells using miRVana Isolation Kit (Ambion, Life Technologies, Milan, Italy) according to the manufacturer's recommendations. The RNA concentrations were determined using Gene5 2.01 Software in Synergy H1 Hybrid Multi-Mode Microplate Reader (BioTek, AHSI, Milan Italy). cDNA for miRNA expression was synthesized from $100 \mathrm{ng}$ of total RNA using the TaqMan microRNA Reverse Transcription Kit (Applied Biosystems, Life Technologies, Milan, Italy) and the expression levels of miR-221 were quantified by TaqMan microRNA Assay Kit (Applied Biosystems, Life Technologies, Milan, Italy). Real-time PCR analysis for mature miR-221 was performed using the primers for the internal control RNU6B (assay ID 001093) and miR-221 (assay ID 000524). In order to measure the mRNA levels of A20 and CTGF, $2 \mu \mathrm{g}$ of total RNA were reversely transcribed using the murine leukaemia virus reverse transcriptase (Life Technologies, Milan, Italy), as indicated by the manufacturer. The quantitative PCR was performed using SYBR Green PCR Master Mix (Applied Biosystems, Life Technologies, Milan, Italy). Specific primers for Actin, which was used as internal control, A20 and CTGF genes were designed using Primer Express version 2.0 software (Applied Biosystems Inc., Milano, Italy). The sequences were as follows: Actin Fwd: 5'AAGCCAACCCCACTTCTCTCTAA-3' and Rev.: 5'-CA CCTCCCCTGTGTGGACTT-3'; A20 Fwd: 5'-CTTGTG GCGCTGAAAACGAA-3' and Rev.: 5'-CTGAACGCCCCACATGTACT-3'; CTGF Fwd: 5'-GGCCCAGACCCAACTATGATT-3' and Rev.: 5'-GAACAGGCGCTCCA CTCTGT-3'. All experiments were performed in triplicate using QuantStudio 6\&7 Flex Real Time PCR System (Applied Biosystems, Life Technologies, Milan, Italy). The data were normalized to the geometric mean of 
housekeeping gene to control the variability into expression levels and fold changes were calculated by relative quantification compared to respective scrambled controls.

\section{Western blotting}

Cells were maintained in complete medium before the transfection assays, which are performed in medium without serum for $48 \mathrm{~h}$ and then lysed in RIPA buffer containing a mixture of protease inhibitors. Equal amounts of protein extract were resolved on SDS-polyacrylamide gel, transferred to a nitrocellulose membrane (Amersham Biosciences, Italy), probed overnight at $4{ }^{\circ} \mathrm{C}$ with antibodies against: A20 (A-12, sc-166,692) and B-Actin (AC-15, sc69,879) (Santa Cruz Biotechnology, DBA, Italy), CTGF (Origene, DBA, Milan, Italy), c-Rel (Cell Signaling Technology, Milan, Italy) and then revealed using the ECL ${ }^{\mathrm{mm}}$ Western Blotting Analysis System (GE Healthcare, Italy).

\section{Chromatin ImmunoPrecipitation (ChIP) assays}

The day before ChIP analysis, cells were shifted to medium lacking serum and then transfected for $48 \mathrm{~h}$ with miR-Ctrl and $25 \mathrm{nM}$ miR-221 alone or in presence of $100 \mathrm{nM}$ LNA-i-miR-221. ChIP assay was performed as previously described [35]. In brief, the immune cleared chromatin was immunoprecipitated with anti c-Rel or non specific IgG (Santa Cruz Biotecnology, DBA), used as negative control. A $4 \mu \mathrm{l}$ volume of each sample and input DNA was used as template to amplify, by real-time PCR a region containing a NF-kB binding site located within the promoter region of CTGF. The primer sequences were: 5'-ACGGAGGAATGCTGAGTGTC-3' (forward) and 5'GGCGGCCGAGGCTTTTATAC-3' (reverse). Real-time PCR data were normalized respect to unprocessed lysates (Input) and the results were reported as fold changes respect to non specific IgG.

\section{Luciferase assays}

Cells were seeded in regular growth medium into 24-well plates. The next day the growth medium was replaced with medium lacking serum and the transfection was performed using X-tremeGene9 reagent, as recommended by the manufacturer (Roche Diagnostics), with a mixture containing CTGF-luc, the internal control pRL-TK, miR-Ctrl or miR-221, alone or in presence of LNA-i-miR-221, shRNA or shRel, alone or in combination with miR-221. Luciferase activity was measured after $48 \mathrm{~h}$ using the Dual Luciferase kit (Promega, Milan, Italy) according to the manufacturer's instructions. Firefly luciferase values were normalized to the internal transfection control provided by the Renilla luciferase activity. The normalized relative light unit (RLU) values obtained from cells transfected with respective scrambled controls were set as 1-fold induction upon which the activity induced by miR-221 was calculated.

\section{Cell proliferation assays}

For quantitative proliferation assay, cells $\left(1 \times 10^{4}\right)$ were seeded in 24-well plates in regular growth medium. Cells were washed, once they had attached, and then incubated in medium containing $2.5 \%$ charcoal stripped fetal bovine serum, before the transfection with $25 \mathrm{nM}$ miR-221, $100 \mathrm{nM}$ LNA-i-miR-221 and $500 \mathrm{ng}$ of the indicated short hairpins. After $48 \mathrm{~h}$ the medium was changed and cell transfection was renewed. Evaluation of cell growth was performed on day 6 using automatic counter (Countess ${ }^{\text {Thx }}$-Invitrogen).

\section{Colony formation assays}

For colony formation assays, cells were transfected as indicated, and then seeded into 6-well plates $\left(2.5 \times 10^{4}\right.$ or $5 \times 10^{4}$ cells per well). The transfections were renewed every 2 days during the assay. After 10 days of incubation, cells were washed with PBS, fixed in acetone:methanol (1:1) for $3 \mathrm{~min}$ at room temperature and then stained with $0.5 \%$ crystal violet in $20 \%$ methanol for $5 \mathrm{~min}$ or Giemsa for $10 \mathrm{~min}$. Pictures were captured by using a digital camera. Colonies, with over 50 cells, were counted using the program WCIF ImageJ for Windows.

\section{Migration assays}

Migration assays were performed by using boyden chambers (Costar Transwell, $8 \mathrm{~mm}$ polycarbonate membrane, Sigma Aldrich, Milan, Italy). Cells were transfected with $25 \mathrm{nM}$ miR-221, $100 \mathrm{nM}$ LNA-i-miR-221 and $500 \mathrm{ng} /$ well shRel or shCTGF as indicated, in medium without serum for $48 \mathrm{~h}$ and then seeded in the upper chambers. In the bottom of the chambers was added regular medium. $8 \mathrm{~h}$ after seeding the cells on the bottom side of the membrane were fixed, stained with Giemsa and counted by using Cytation 3 Cell Imaging Multimode Reader (BioTek, Winooski, VT).

\section{Statistical analysis}

Data were analysed by one-way ANOVA with Dunnett's multiple comparisons where applicable, using GraphPad Prism version 6.01 (GraphPad Software, Inc., San Diego, CA, USA). $p<0.05\left(^{(*)}\right.$ and $p<0.01(* *)$ were considered statistically significant.

\section{Results}

miR-221 down-regulates A20 expression in CAFs, MDA-MB 231 and $\mathrm{SkBr} 3$ breast cancer cells

On the basis of previous studies showing that miR-221 may act as an oncogenic factor in certain malignancies (reviewed in [11]), we began the present investigation assessing that the levels of the endogenous miR-221 are higher in crucial players of the tumor microenvironment as CAFs and in both MDA-MB 231 
and $\mathrm{SkBr} 3$ breast cancer cells respect to normal fibroblasts and non-transformed MCF10A breast cells (Fig. 1a). In order to provide novel insights into the mechanisms through which miR-221 elicits a tumorigenic action, we then ascertained that the miR-221 inhibitor named LNA-i-miR-221 effectively reduces the levels of miR-221, which was ectopically expressed in CAFs, MDA-MB 231 and SkBr3 cells (Fig. 1b). Using available bioinformatics tools (http://www. microrna.org; http://www.targetscan.org; http://ophid.utoronto.ca/mirDIP/), we identified a putative miR-221 binding site in 3'-UTR region of the ubiquitin-editing enzyme TNFAIP3, namely A20 (Fig. 1c), recently also demonstrated through luciferase assay in macrophages by Zhao et al. [16].
In accordance with these findings, we ascertained that the ectopic expression of miR-221 lowers mRNA and protein levels of A20 in CAFs, MDA-MB 231 and SkBr3 cells (Fig. 1d-g), however these effects were no longer evident in the presence of LNA-i-miR-221 (Fig. 1d-g). Altogether, our results point to the ability of miR-221 in regulating A20 expression in our model system.

\section{miR-221 prompts the expression of c-Rel and its recruitment to the CTGF promoter region in CAFs, MDA-MB 231 and SkBr3 breast cancer cells}

Previous studies have shown that A20 may regulate NF-kB, in particular a negative correlation between the levels of
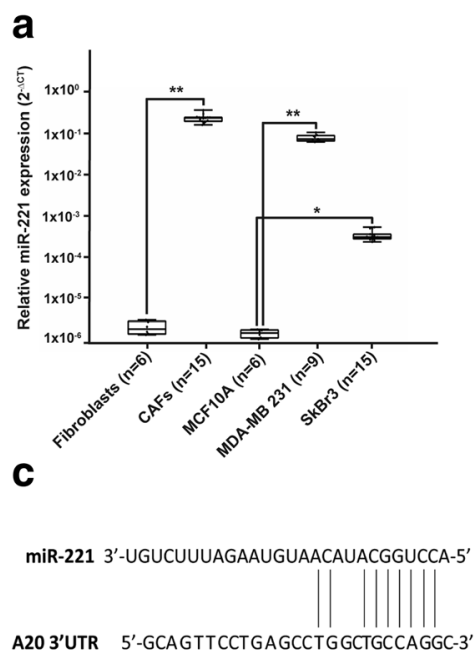

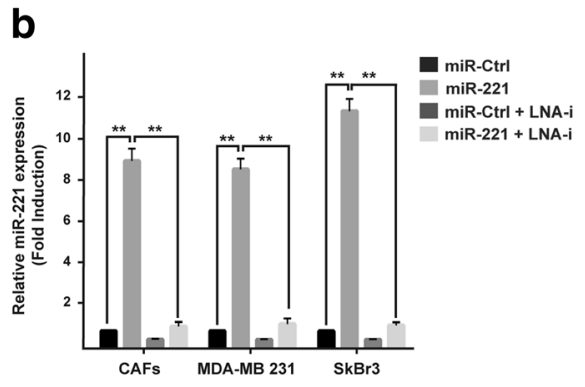

d

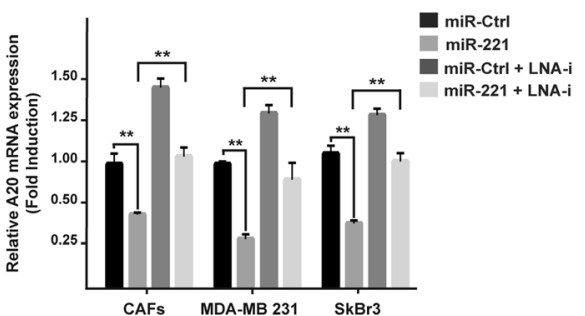

g

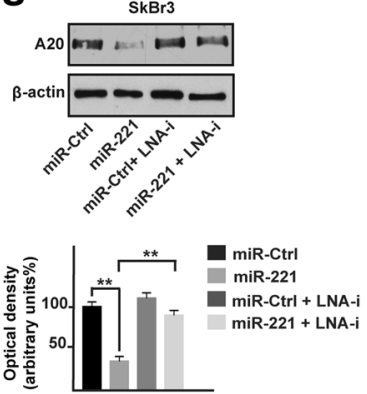

Fig. 1 miR-221 regulates A20 expression in CAFs and breast cancer cells. a Expression of miR-221 in fibroblasts, CAFs, MCF10A, MDA-MB 231 and SkBr3 cells. Raw Ct data were normalized to the housekeeping RNU6 levels and expressed as $\Delta \mathrm{Ct}$ values using the comparative cross threshold (Ct) method. $\mathbf{b}$ miR-221 expression in CAFs, MDA-MB 231 and SkBr3 breast cancer cells after transfection for $48 \mathrm{~h}$ with $25 \mathrm{nM}$ miR-Ctrl and $25 \mathrm{nM}$ miR-221, alone or in combination with $100 \mathrm{nM}$ LNA-i-miR-221 (LNA-i). c Schematic alignment between the miR-221 sequence and the 3'-UTR mRNA region of A20. d A20 mRNA expression in CAFs, MDA-MB 231 and SkBr3 cells transfected for $48 \mathrm{~h}$ with $25 \mathrm{nM}$ miR-Ctrl and $25 \mathrm{nM}$ miR-221, alone or in combination with 100 nM LNA-i-miR-221 (LNA-i). A20 protein expression in CAFs (e), MDA-MB 231 (f) and SkBr3 (g) cells transfected for $48 \mathrm{~h}$ with $25 \mathrm{nM}$ miR-Ctrl and $25 \mathrm{nM}$ miR-221, alone or in in combination with $100 \mathrm{nM} \mathrm{LNA-i-miR-221} \mathrm{(LNA-i);} \beta$-actin serves as a loading control. Below panels show densitometric analysis of the blots normalized to the loading controls. Each column represents the mean \pm SD of three independent experiments performed in triplicate. The data are shown as fold induction respect to cells transfected with miR-Ctrl. ( $\left(^{*}\right)$ indicates $p<0.05$ and $(* *) p<0.01$ 
A20 and the expression of a NF-kB component named cRel has been reported [29]. In this vein, we found that the miR-221 dependent c-Rel protein expression was no longer evident in the presence of LNA-i-miR-221 in CAFs, MDA-MB 231 and SkBr3 cells (Fig. 2a-c). As NF-kB activity has been demonstrated to regulate CTGF expression [32, 33], we analyzed the CTGF promoter sequence (http://www.ncbi.nlm.nih.gov; http://alggen.lsi.upc. es/; http://www.generegulation.com) identifying a putative NF-kB binding site (Fig. 2d). Worthy, performing a ChIP analysis we assessed that the recruitment of c-Rel to the CTGF promoter sequence induced by miR-221 is abrogated a
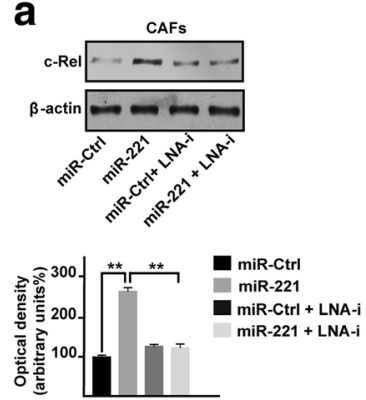

d

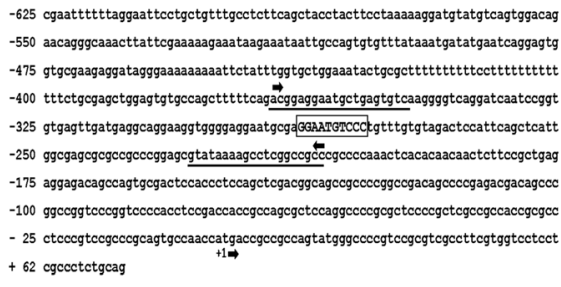

f

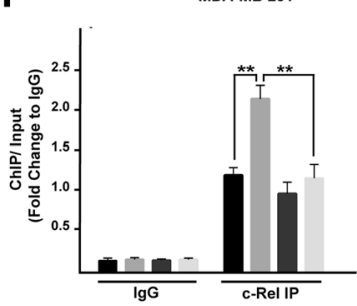

$\mathbf{h}$

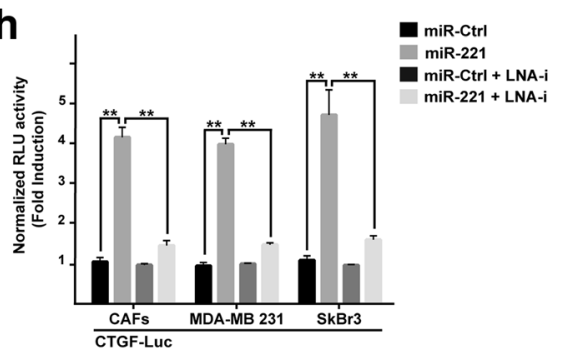

b
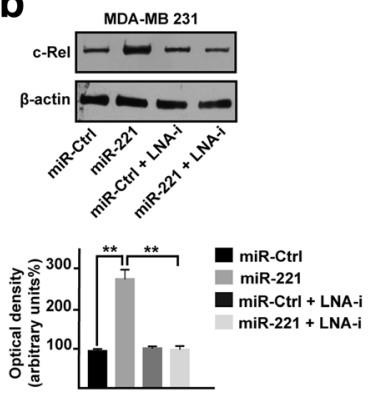

e

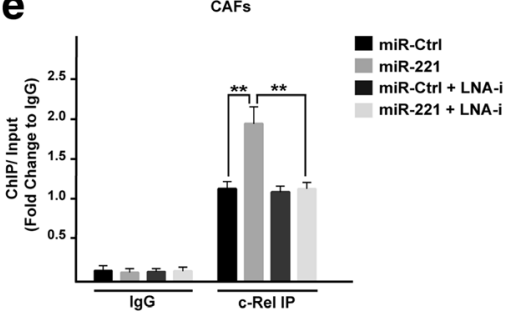

$\mathbf{g}$

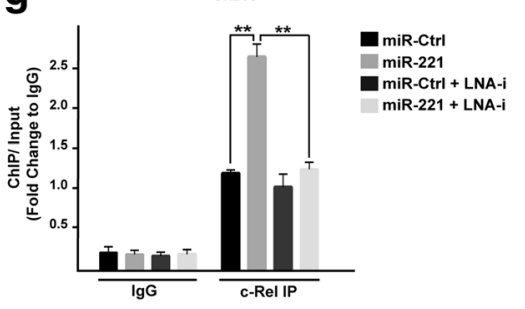

i

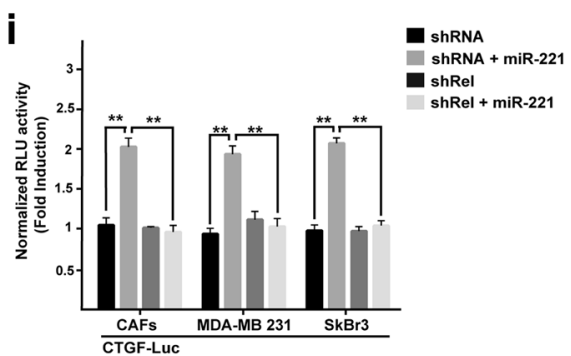

Fig. 2 miR-221 prompts the protein expression of c-Rel and its recruitment to the CTGF promoter region. c-Rel protein expression in CAFs (a), MDA-MB 231 (b) and SkBr3 (c) cells transfected for $48 \mathrm{~h}$ with $25 \mathrm{nM}$ miR-Ctrl and $25 \mathrm{nM}$ miR-221, alone or in combination with $100 \mathrm{nM}$ LNA-i-miR-221 (LNA-i). ß-actin serves as a loading control. Below panels show densitometric analysis of the blots normalized to the loading controls. $\mathbf{d}$ Putative NF-kB binding site (capital letters in the rectangle) located within the CTGF promoter sequence ( $-625 \mathrm{bp}$ to $+62 \mathrm{bp}$ ). The transcriptional start site is indicated as +1 . The position of primers used for ChIP-qPCR analyses is underlined. Recruitment of c-Rel to the NF-kB binding site within the CTGF promoter sequence in CAFs (e), MDA-MB 231 ( $\mathbf{f}$ ) and SkBr3 (g) cells transfected for $48 \mathrm{~h}$ with $25 \mathrm{nM}$ miR-Ctrl and $25 \mathrm{nM}$ miR-221, alone or in combination with $100 \mathrm{nM}$ LNA-i-miR-221 (LNA-i). Data were normalized to the Input and reported as fold changes respect to $\mathrm{IgG}$. $\mathbf{h}$ Luciferase activity of the CTGF reporter gene in CAFs, MDA-MB 231 and SkBr3 cells transfected for $48 \mathrm{~h}$ with $25 \mathrm{nM}$ miR-Ctrl and $25 \mathrm{nM}$ miR-221, alone or in combination with $100 \mathrm{nM}$ LNA-i-miR-221 (LNA-i). i Luciferase activity of the CTGF reporter gene in CAFs, MDA-MB 231 and SkBr3 cells transfected for $8 \mathrm{~h}$ with shRNA or shRel and then transfected for $48 \mathrm{~h}$ with $25 \mathrm{nM}$ miR-221. The luciferase activity was normalized to the internal transfection control; values of cells receiving scrambled controls were set as 1 -fold induction upon which the activity obtained with the indicated effectors was calculated. Each column represents the mean \pm SD of three independent experiments performed in triplicate. $\left({ }^{*}\right)$ indicates $p<0.01$ 
in the presence of LNA-i-miR-221 (Fig. 2e-g). Moreover and in agreement with these results, the transactivation of a CTGF-luc reporter construct by miR-221 was repressed by LNA-i-miR-221 (Fig. 2h) as well as by shRNA silencing of cRel expression (Fig. 2i). In accordance with these results, the up-regulation of CTGF by miR-221 at both mRNA and protein levels was abolished by LNA-i-miR-221 (Fig. 3a, c-e) or c-Rel knock-down (Fig. 3b, f-k). Collectively, these data suggest that c-Rel is involved in the up-regulation of
CTGF expression by miR-221 in CAFs, MDA-MB 231 and $\mathrm{SkBr} 3$ cells.

miR-221 induces growth and migratory effects through c-Rel and CTGF in CAFs, MDA-MB 231 and SkBr3 breast cancer cells

As a biological counterpart of the results described above, we ascertained that the proliferative responses elicited by miR-221 are prevented in the presence of LNA-i-miR-221

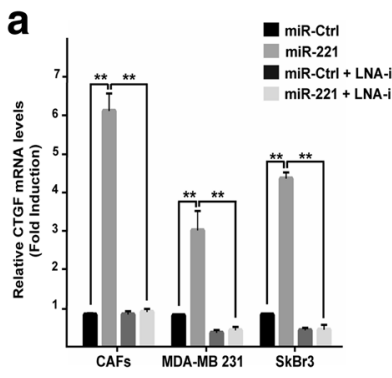

C
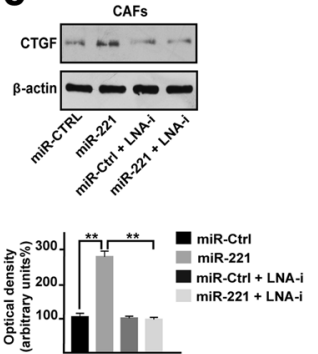

f
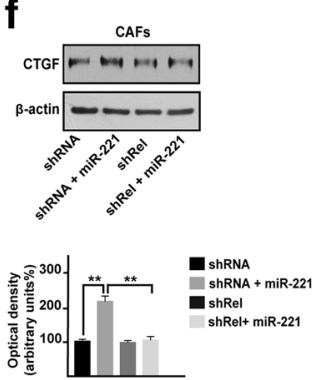

i

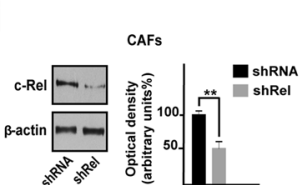

d
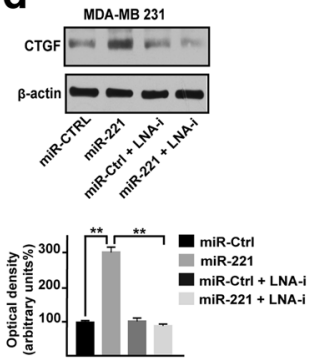

g
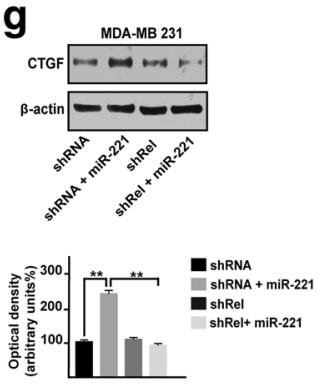

j

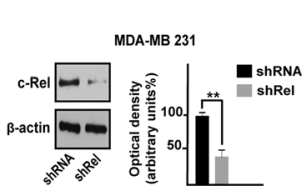

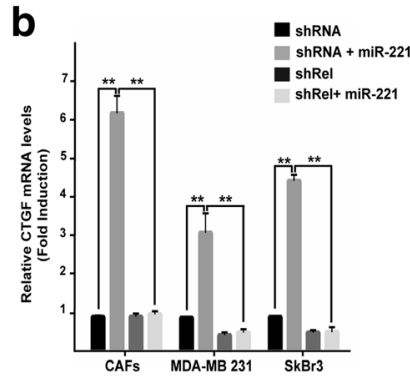

e
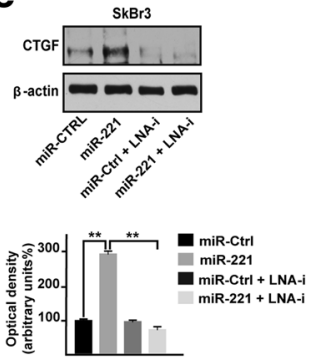

h
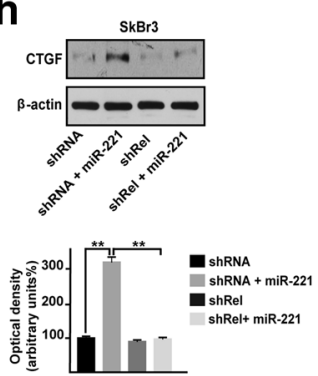

k

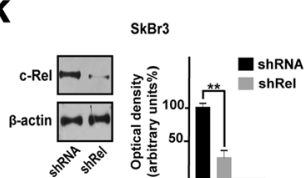

Fig. 3 c-Rel is involved in the up-regulation of the CTGF triggered by miR-221. a CTGF mRNA levels in CAFs, MDA-MB 231 and SkBr3 cells transfected for $48 \mathrm{~h}$ with $25 \mathrm{nM}$ miR-Ctrl and $25 \mathrm{nM}$ miR-221, alone or in combination with $100 \mathrm{nM}$ LNA-i-miR-221 (LNA-i). Data are shown as fold changes respect to the scrambled controls. $\mathbf{b}$ CTGF mRNA levels in CAFs, MDA-MB 231 and SkBr3 cells transfected for $8 \mathrm{~h}$ with shRNA or shRel and then transfected for $48 \mathrm{~h}$ with $25 \mathrm{nM}$ miR-221. Data are shown as fold changes respect to the scrambled controls. CTGF protein levels in CAFs (c), MDA-MB 231 (d) and SkBr3 (e) cells transfected for $48 \mathrm{~h}$ with $25 \mathrm{nM}$ miR-Ctrl and $25 \mathrm{nM}$ miR-221, alone or in combination with $100 \mathrm{nM}$ LNA-i-miR-221 (LNA-i). $\beta$-actin serves as a loading control. Below panels show densitometric analysis of the blots normalized to the loading controls. CTGF protein levels in CAFs (f), MDA-MB $231(\mathbf{g})$ and SkBr3 $(\mathbf{h})$ cells transfected for $8 \mathrm{~h}$ with shRNA or shRel and then transfected for $48 \mathrm{~h}$ with $25 \mathrm{nM}$ miR-221. $\beta$-actin serves as a loading control. Below panels show densitometric analysis of the blots normalized to the loading controls. Efficacy of c-Rel silencing in CAFs (i), MDA-MB 231 (j) and SkBr3 (k) cells. $\beta$-actin serves as a loading control. Side panels show densitometric analysis of the blots normalized to the loading controls. Results shown are representative of at least three independent experiments. $\left({ }^{*}\right)$ indicates $p<0.01$ 
(Fig. 4a, d, g), or by c-Rel silencing (Fig. 4b, e, h) and CTGF induced expression (Fig. 4c, f, i) in CAFs, MDAMB 231 and SkBr3 cells. By colony formation assay, we then assessed that the clonogenic capacity induced by miR-221 in CAFs, MDA-MB 231 and SkBr3 is no longer evident in the presence of LNA-i-miR-221 (Fig. 5a, c, e), or by shRNA mediated silencing of c-Rel (Fig. 5b, d, f) or by CTGF expression (data not shown). Performing Boyden chamber assay in CAFs, MDA-MB-231 and SkBr3 cells, we also determined that the migratory effects stimulated by miR-221 are abolished using LNA-i-miR221 (Fig. 6a, c, e), knocking-down c-Rel (Fig. 6b, d, f) or CTGF expression (data not shown). Overall, these results indicate that both c-Rel and CTGF are involved in the proliferative and migratory effects triggered by miR-221 in our model system.

\section{Discussion}

In the present study, we have ascertained novel molecular mechanisms by which miR-221 may exert an oncogenic action in breast cancer. In particular, we have shown that miR-221 could trigger proliferative and migratory effects through the interference with A20/c-Rel/CTGF signaling in main players of the tumor microenvironment as CAFs, in MDA-MB 231 and SkBr3 breast cancer cells. Worthy, these biological responses were prevented using the synthetic inhibitor of miR-221 namely LNA-i-miR-221 or silencing c-Rel and CTGF expression. Overall, our data provide novel evidence on the oncogenic role of miR-221, hence suggesting the usefulness of its inhibition in further preventive and therapeutic strategies against breast tumor.

Breast cancer is a heterogeneous disease that includes various subtypes, with different biological behaviour and clinical outcome [49]. Based on the gene expression profile, three major subtypes of breast cancer have been identified: the luminal (A and B), the basal-like and the epidermal growth factor receptor 2 overexpressing type [49]. The breast cancer subtype expressing hormone receptors, usually identified as luminal $\mathrm{A}$ and $\mathrm{B}$, have a favourable prognosis undergoing anti-hormone treatments
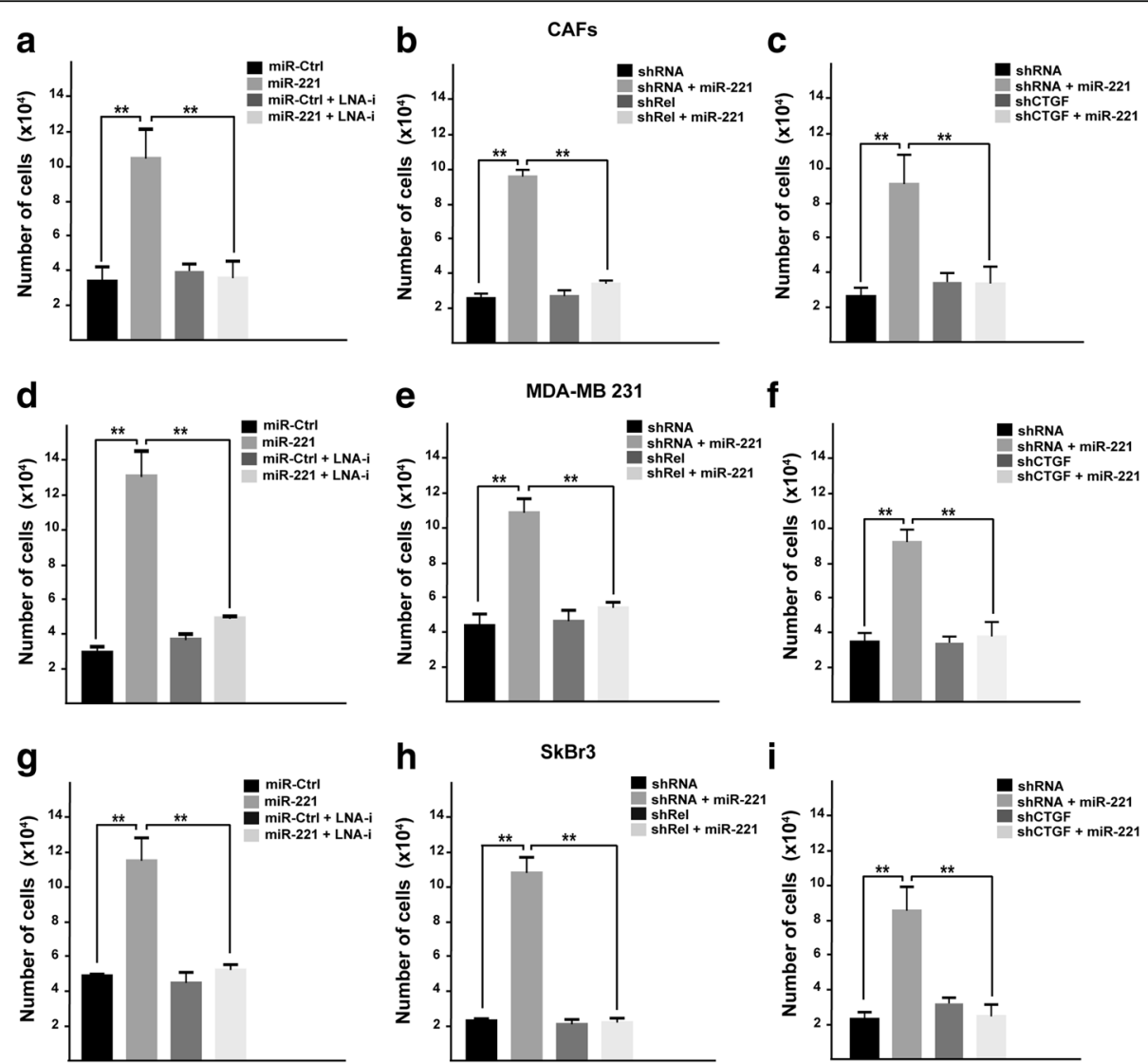

Fig. 4 miR-221 induces proliferative effects in CAFs, MDA-MB 231 and SkBr3 cells. Cell proliferation in (a) CAFs, (d) MDA-MB 231 and (g) SkBr3 cells transfected every 2 days with $25 \mathrm{nM}$ miR-Ctrl and $25 \mathrm{nM}$ miR-221, alone or in combination with $100 \mathrm{nM}$ LNA-i-miR-221 (LNA-i) and then counted on day 6. Cell proliferation in CAFs (b) MDA-MB 231 (e) and SkBr3 (h) cells transfected with shRNA or shRel for $8 \mathrm{~h}$ and then transfected for $48 \mathrm{~h}$ with $25 \mathrm{nM}$ miR-221. Cell proliferation in CAFs (c), MDA-MB 231 (f) and SkBr3 (i) cells transfected with shRNA or shCTGF for $8 \mathrm{~h}$ and then transfected for $48 \mathrm{~h}$ with $25 \mathrm{nM}$ miR-221. The transfections were renewed every 2 days and cells were counted on day 6 . Each data point is the mean $\pm \mathrm{SD}$ of three independent experiments performed in triplicate. $\left.{ }^{* *}\right)$ indicates $p<0.01$ 


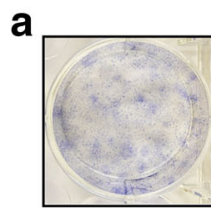

miR-Ctrl

b

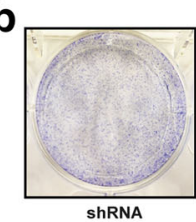

shRNA

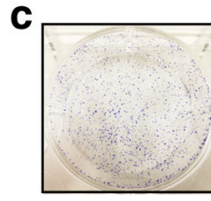

miR-Ctrl

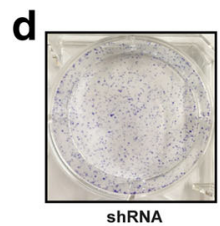

ShRNA

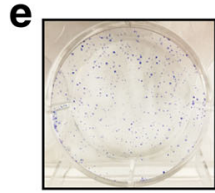

miR-Ctrl

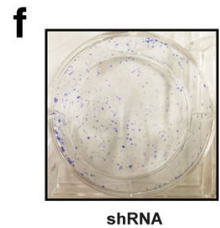

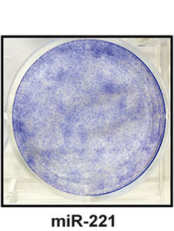
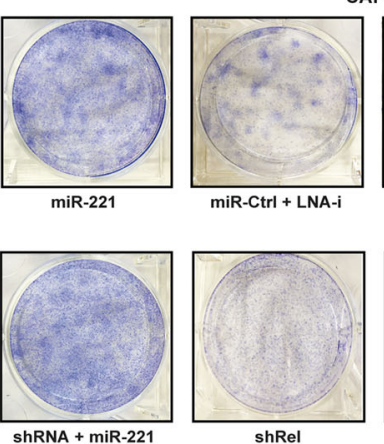

CAFs
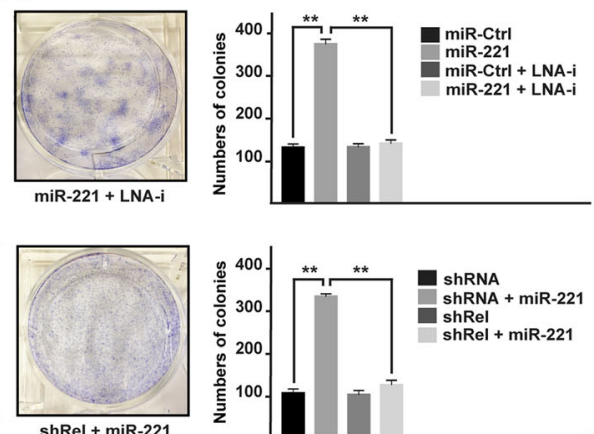

shRel + miR-221

MDA-MB 231
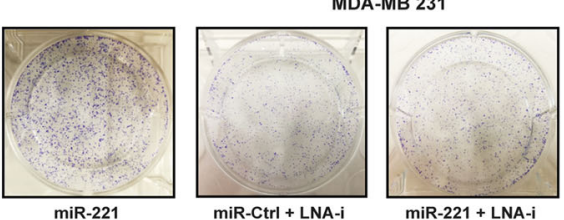

miR-221 + LNA-i
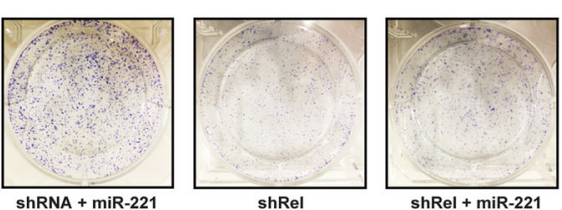

shRel + miR-221

SkBr3
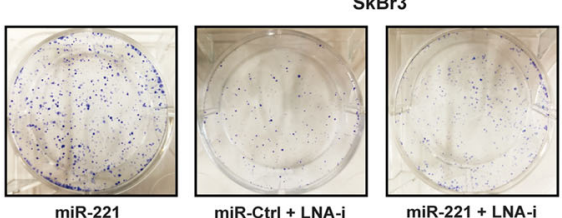

miR-221 + LNA-i
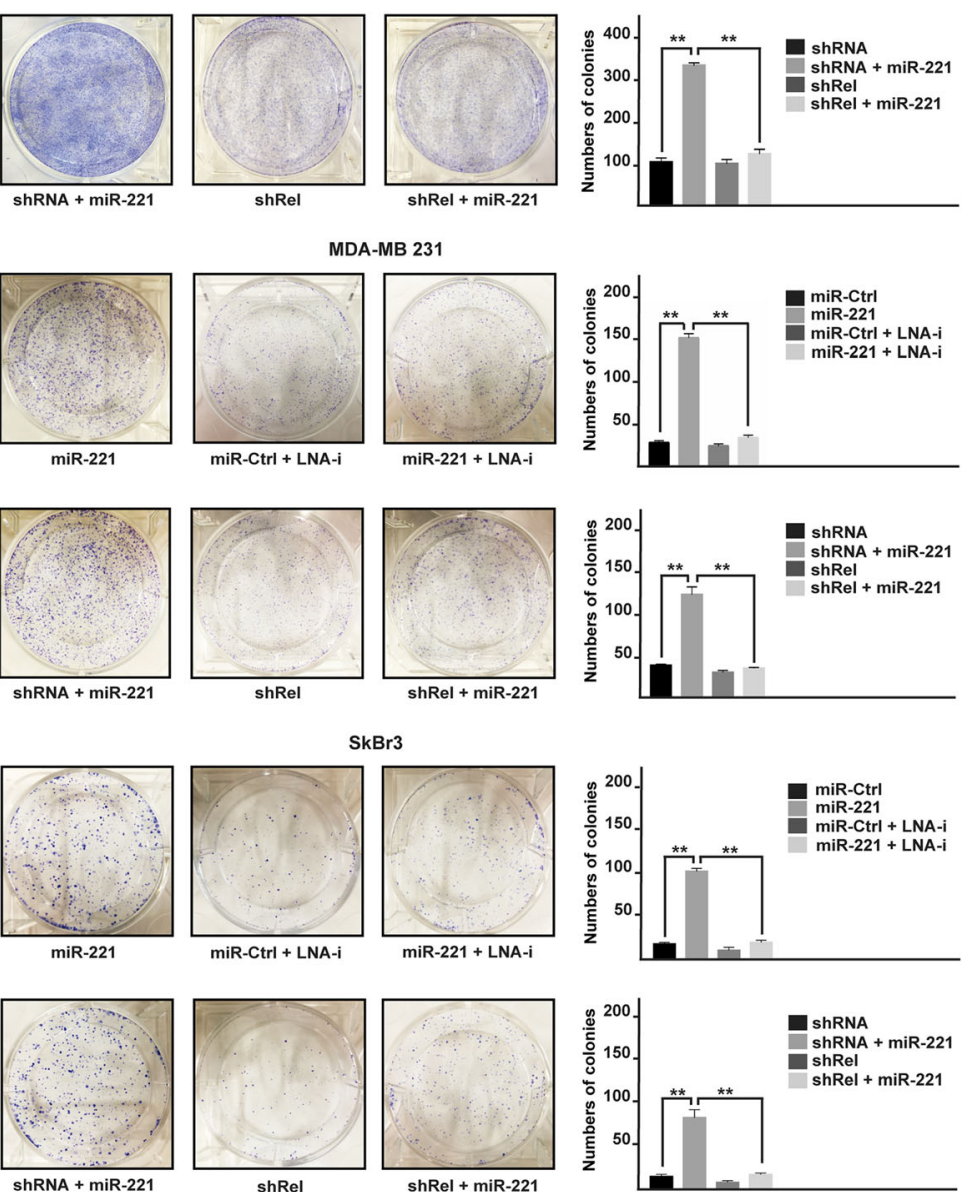

Fig. 5 miR-221 promotes colony formation in CAFs, MDA-MB 231 and SkBr3 cells. Colony formation in CAFs (a, b), MDA-MB 231 (c, d) and SkBr3 $(\mathbf{e}, \mathbf{f})$ cells transfected every 2 days as indicated, after 10 days of incubation cell colonies were stained and pictures were captured by a digital camera. Colonies were counted using the program WCIF ImageJ for Windows. Each data point is the mean \pm SD of three independent experiments performed in triplicate. $\left.{ }^{* *}\right)$ indicates $p<0.01$

[50]. Tumors overexpressing the epidermal growth factor receptor 2 are treated with anti HER2 monoclonal antibodies as trastuzumab and pertuzumab or with immunoconjugates as TDM1 or kinase inhibitors as lapatinib or neratinib, mostly combined [51], whereas the triplenegative breast cancer that is treated with conventional and moderately successful chemotherapies displays a poor prognosis and a high risk of relapse [52, 53]. Presently, there is increasing evidence that components of the tumor microenvironment, as CAFs, may play a main role in cancer progression and invasiveness [42, 54]. The growth characteristics of CAFs are different from those of fibroblasts associated with normal breast epithelial cells [55]. In particular, CAFs associated with invasive breast carcinoma cells show an abnormal migratory behaviour in vitro [55], altered levels of growth factors like CTGF [56] and insulinlike growth factors I and II [57], increased expression of inflammatory genes [58]. In addition, several studies have recently suggested that every cellular process is likely regulated by miRNAs and aberrant miRNAs expression may play a pathogenic role in several diseases, including cancer $[7,59]$. Among dysregulated miRNAs, miR-221 is of relevant interest since it is strongly upregulated in a variety of hematologic and solid malignancies, including breast cancer (reviewed in [11]). In particular, increased levels of miR-221, which form a cluster together with miR-222 
a

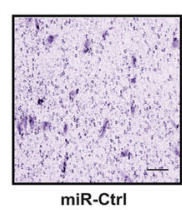

b

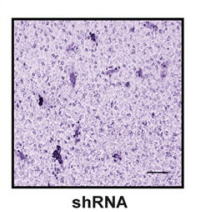

C

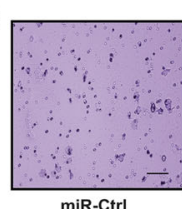

d

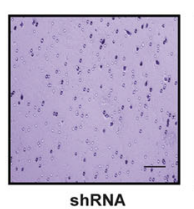

e

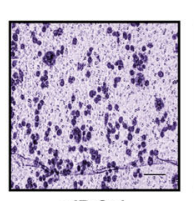
miR-Ctrl

f

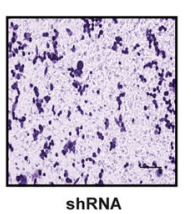

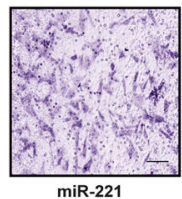

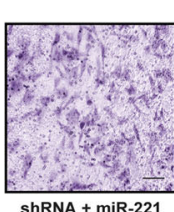

shRNA + miR-221
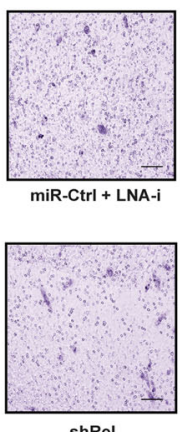

CAFs

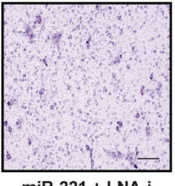

miR-221 + LNA-i

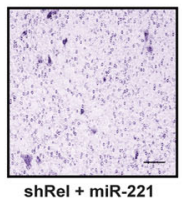

MDA-MB 231
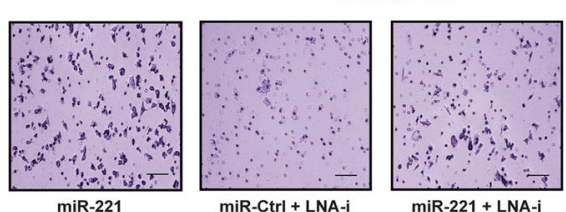

miR-221 + LNA-i
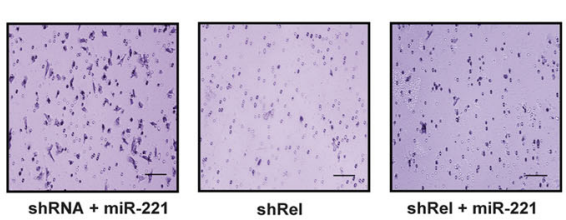

SkBr3
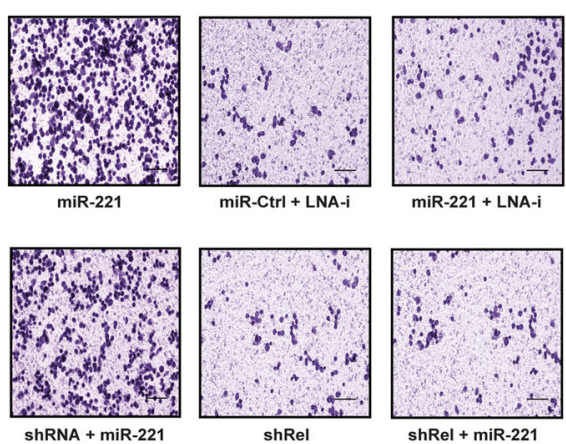
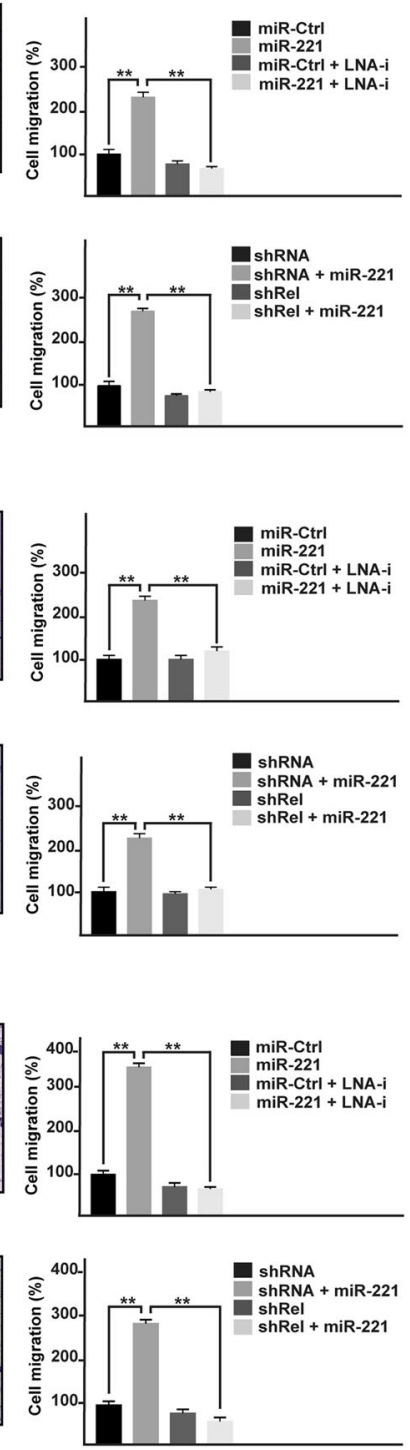

Fig. 6 miR-221 triggers migratory effects in CAFs, MDA-MB 231 and SkBr3 cells. Cell migration as evaluated by Boyden Chamber assay in (a) CAFs, (c) MDA-MB 231 and (e) SkBr3 cells transfected for $48 \mathrm{~h}$ with $25 \mathrm{nM}$ miR-Ctrl and $25 \mathrm{nM}$ miR-221, alone or in combination with $100 \mathrm{nM}$ LNA-i-miR-221 (LNA-i). Cell migration, evaluated by Boyden Chamber assay, in CAFs (b) MDA-MB 231 (d) and SkBr3 (f) cells transfected with shRNA or shRel for $8 \mathrm{~h}$ and then transfected for $48 \mathrm{~h}$ with $25 \mathrm{nM}$ miR-221. Cells were counted in at least 10 random fields at 10x magnification (Scale bar $=200 \mu \mathrm{m})$ in three independent experiments performed in triplicate. $\left.{ }^{* *}\right)$ indicates $p<0.01$

within the human chromosome $\mathrm{X}$, have been related to the invasion of breast cancer cells and advanced clinical stages in breast tumor patients [60]. Hence, targeting miR-221 by specific inhibitors like LNA-i-miR-221 may represent a new promising strategy to overcome cancer progression, as in breast tumor [42-45].

In this scenario, we provide a better understanding of the molecular mechanism through which miR-221 may be involved in the progression of breast cancer. First, we have found that in CAFs, in MDA-MB 231 and SkBr3 breast cancer cells, miR-221 down-regulates the expression of the ubiquitin-editing enzyme, A20, at both
mRNA and protein levels. These results are consistent with previous data obtained in other cell contexts, showing that miR-221 directly targets the 3'-UTR region of A20 [16]. A20 is a Cys2/Cys2 zinc finger protein, which is induced by a variety of inflammatory stimuli and acts as a negative regulator of NF-kB $[16,18]$. Of note, NF-kB signaling is tightly controlled by ubiquitination and A20, through its de-ubiquitinating activity, is one of the proteins that affects this process. For instance, it has been suggested that A20 induces the ubiquitination of the paracaspase MALT1, thus preventing the formation of the MALT1-IkB kinase complex and the consequent 
activation of the NF- $\mathrm{kB}$ signaling that mainly involves the heterodimers RelA, c-Rel, and p50 [29]. In agreement with these observations, we also found that miR-221 induces c-Rel expression, therefore suggesting that miR221 may regulate NF-kB action. Interacting with other components of the NF-kB complex, c-Rel forms dimers that binding to specific sequences in the promoter region of target genes modulate gene expression [30]. By bioinformatic analysis, we found a putative NF-kB binding site located within the CTGF promoter sequence and we demonstrated that miR-221 induces the recruitment of c-Rel within the CTGF promoter region, toward an increase of CTGF expression. Corroborating these findings, we finally assessed that the growth and migratory effects induced by miR-221 in CAFs, MDA-MB 231 and SkBr3 cells, are prevented by LNA-i-miR-221 or by silencing of c-Rel and CTGF expression.

\section{Conclusions}

In summary, our data show that miR-221 elicits a stimulatory action not only in breast cancer cells but also in main component of the tumor microenvironment like CAFs, through the involvement of A20/c-Rel/CTGF signaling. Consequently, the inhibition of miR-221 by LNA-i-miR221 may be considered in novel therapeutic approaches in breast cancer.

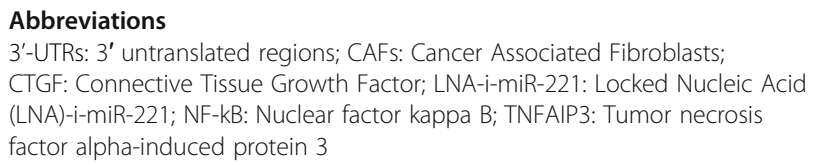

\section{Funding}

This work has been supported by the Italian Association for Cancer Research (AIRC), Special Program Molecular Clinical Oncology - 5 per mille n. 9980, 2010/ 15 PI: PT and $5 \times 1000$ Molecular Clinical Oncology Extension Program, n.9980, 2016/18 PI: PT and partially by Innovative immunotherapeutic treatments of human cancer, MultiUnit - Multi Unit Regional n.16695 (co-financed by AIRC and CARICAL foundation), 2015/18 PI: PT. MM was supported by (AIRC, IG 16719). MFS was supported by Fondazione Umberto Veronesi (Post-Doctoral Fellowship 2018)

\section{Availability of data and materials}

All data analysed during this study are included in this manuscript.

\section{Authors' contributions}

AV, MTDM and MM conceived and designed the study. AV, MFS, RL, FC, DCR, AS performed the experiments. AV, MFS, RL, FC, DCR, AS, SA acquired material and data. AV, MM, PT, PT, MTDM analysed and interpreted the data. AV, MM, PT, PT, MTDM wrote and reviewed the manuscript. All authors have read and approved the final manuscript.

\section{Ethics approval and consent to participate}

Signed informed consent from all the patients was obtained and all samples were collected, identified and used in accordance with approval by the Institutional Ethical Committee Board (Regional Hospital, Cosenza, Italy).

\section{Competing interests}

The authors declare that they have no competing interest.

\section{Publisher's Note}

Springer Nature remains neutral with regard to jurisdictional claims in published maps and institutional affiliations.

\section{Author details}

'Department of Pharmacy, Health and Nutritional Sciences, University of Calabria, Rende, Italy. ${ }^{2}$ Regional Hospital Cosenza, Cosenza, Italy. ${ }^{3}$ Department of Experimental and Clinical Medicine, Magna Graecia University, Catanzaro, Italy.

Received: 15 March 2018 Accepted: 20 April 2018

Published online: 02 May 2018

\section{References}

1. Bartel DP. MicroRNAs: target recognition and regulatory functions. Cell. 2009;136:215-33.

2. Ben-Hamo R, Efroni S. MicroRNA regulation of molecular pathways as a generic mechanism and as a core disease phenotype. Oncotarget. 2015; 6:1594-604

3. Wu Z, Huang X, Huang X, Zou Q, Guo Y. The inhibitory role of Mir-29 in growth of breast cancer cells. J Exp Clin Cancer Res. 2013;32:98.

4. Wang C, Zheng X, Shen C, Shi Y. MicroRNA-203 suppresses cell proliferation and migration by targeting BIRC5 and LASP1 in human triple-negative breast cancer cells. J Exp Clin Cancer Res. 2012;31:58

5. Paladini L, Fabris L, Bottai G, Raschioni C, Calin GA, Santarpia L. Targeting microRNAs as key modulators of tumor immune response. J Exp Cancer Res. 2016;35:103.

6. Smigal C, Jemal A, Ward E, Cokkinides V, Smith R, Howe HL, et al. Trends in breast cancer by race and ethnicity: update 2006. CA Cancer J Clin. 2006;56:168-83.

7. Iorio MV, Ferracin M, Liu CG, Veronese A, Spizzo R, Sabbioni S, et al. MicroRNA gene expression deregulation in human breast cancer. Cancer Res. 2005;65:7065-70.

8. Song B, Wang C, Liu J, Wang X, Lv L, Wei L, et al. MicroRNA-21 regulates breast cancer invasion partly by targeting tissue inhibitor of metalloproteinase 3 expression. J Exp Clin Cancer Res. 2010;29:29.

9. Vivacqua A, De Marco P, Santolla MF, Cirillo F, Pellegrino M, Panno ML, et al. Estrogenic GPER signaling regulates mir144 expression in cancer cells and cancer-associated fibroblasts (CAFs). Oncotarget. 2015;6:16573-8711.

10. Vivacqua A, De Marco P, Belfiore A, Maggiolini M. Recent advances on the role of microRNAs in both insulin resistance and Cancer. Curr Pharm Des. 2017;23:3658-66.

11. Di Martino MT, Rossi M, Caracciolo D, Gullà A, Tagliaferri P, Tassone P. MiR221 and miR-222 are promising targets for innovative anticancer therapy. Expert Opin Ther Targets. 2016;21:1-10.

12. Han SH, Kim HJ, Gwak JM, Kim M, Chung YR, Park SY. MicroRNA-222 expression as a predictive marker for tumor progression in hormone receptor-positive breast cancer. J Breast Cancer. 2017;20:35-44.

13. Shen H, Wang D, Li L, Yang S, Chen X, Zhou S, et al. Mir-222 promotes drug-resistance of breast cancer cells to adriamycin via modulation of PTEN/Akt/ FOXO1 pathway. Gene. 2017;596:110-8.

14. Di Martino MT, Gullà A, Cantafio ME, Lionetti M, Leone E, Amodio N, et al. In vitro and in vivo anti-tumor activity of miR-221/222 inhibitors in multiple myeloma. Oncotarget. 2013:4:242-55.

15. Fornari F, Gramantieri L, Ferracin M, Veronese A, Sabbioni S, Calin GA, et al. MiR-221 controls CDKN1C/p57 and CDKN1B/p27 expression in human hepatocellular carcinoma. Oncogene. 2008;27:5651-61.

16. Zhao D, Zhuang N, Ding $Y$, Kang $Y$, Shi L. MiR-221 activates the NF-kB pathway by targeting A20. Biochem Biophys Res Commun. 2016;472:11-8.

17. Lappas M. A20, an essential component of the ubiquitin-editing protein complex, is a negative regulator of inflammation in human myometrium and foetal membranes. Mol Hum Reprod. 2017;23:628-45.

18. Düwel M, Welteke V, Oeckinghaus A, Baens M, Kloo B, Ferch U, et al. A20 negatively regulates $T$ cell receptor signaling to NF-kappaB by cleaving Malt1 ubiquitin chains. J Immunol. 2009;182:7718-28.

19. Karin M, Greten FR. NF-kappaB: linking inflammation and immunity to cancer development and progression. Nat Rev Immunol. 2005;5:749-59.

20. Meteoglu I, Erdogdu IH, Meydan N, Erkus M, Barutca S. NF-kappa B expression correlates with apoptosis and angiogenesis in clear cell renal carcinoma tissues. J Exp Clin Cancer Res. 2008;27:53. 
21. Leotoing L, Chereau F, Baron S, Hube F, Valencia HJ, Bordereaux D, et al. A20binding inhibitor of nuclear factorkappaB (NF-kappaB)-2 (ABIN-2) is an activator of inhibitor of NF-kappaB (IkappaB) kinase alpha (IKKalpha)-mediated NFkappaB transcriptional activity. J Biol Chem. 2011;286:32277-e32288.

22. Gao L, Coope H, Grant S, Ma A, Ley SC, Harhaj EW. ABIN1 protein cooperates with TAX1BP1 and A20 proteins to inhibit antiviral signaling. J Biol Chem. 2011;286:36592e36602.

23. Xia M, Liu J, Wu X, Liu S, Li G, Han C, et al. Histone methyltransferase Ash1l suppresses interleukin-6 production and inflammatory autoimmune diseases by inducing the ubiquitin-editing enzyme A20. Immun. 2013;39:470-e481.

24. Zhang X, Dong C, Sun X, Li Z, Zhang M, Guan Z, et al. Induction of the cellular miR-29c by influenza virus inhibits the innate immune response through protection of A20 mRNA. Biochem Biophys Res Commun. 2014;450:755e761.

25. Liu X, He F, Pang R, Zhao D, Qiu W, Shan K, et al. Interleukin-17 (IL-17)induced microRNA 873 (miR-873) contributes to the pathogenesis of experimental autoimmune encephalomyelitis by targeting A20 ubiquitinediting enzyme. J Biol Chem. 2014;289:28971-e28986.

26. Kumar M, Sahu SK, Kumar R, Subuddhi A, Maji RK, Jana K, et al. MicroRNA let-7 modulates the immune response to Mycobacterium tuberculosis infection via control of A20, an inhibitor of the NF-kappaB pathway. Cell Host Microbe. 2015;17:345-e356.

27. Kim SW, Ramasamy K, Bouamar H, Lin AP, Jiang D, Aguiar RC. MicroRNAs miR-125a and miR-125b constitutively activate the NF-kappaB pathway by targeting the tumor necrosis factor alpha-induced protein 3 (TNFAIP3, A20). Proc Natl Acad Sci U S A. 2012;109:7865e.

28. Cortes Sempere M, Rodriguez Fanjul V, Sanchez Perez I, Perona R. The role of the NFkappaB signalling pathway in cancer. Clin Transl Oncol. 2008;10:143-7.

29. Giordano M, Roncagalli R, Bourdely P, Chasson L, Buferne M, Yamasaki S. The tumor necrosis factor alpha-induced protein 3 (TNFAIP3, A20) imposes a brake on antitumor activity of CD8 T cells. Proc Natl Acad Sci U S A. 2014; 111:11115-20

30. Gilmore TD, Gerondakis S. The c-Rel transcription factor in development and disease. Genes Cancer. 2011;2:695-711.

31. Romieu-Mourez R, Kim DW, Shin SM, Demicco EG, Landesman-Bollag E, Seldin DC, et al. Mouse mammary tumor virus c-rel transgenic mice develop mammary tumors. Mol Cell Biol. 2003;23:5738-54.

32. Xue X, Chen Q, Zhao G, Zhao JY, Duan Z, Zheng PS. The overexpression of TGF- $\beta$ and CCN2 in intrauterine adhesions involves the NF-KB signaling pathway. PLoS One. 2015;10:e0146159.

33. Terada Y, Ueda S, Hamada K, Shimamura Y, Ogata K, Inoue K, et al. Aldosterone stimulates nuclear factor-kappa B activity and transcription of intercellular adhesion molecule-1 and connective tissue growth factor in rat mesangial cells via serum- and glucocorticoid-inducible protein kinase-1. Clin Exp Nephrol. 2012;16:81-8.

34. Cicha I, Goppelt-Struebe M. Connective tissue growth factor: contextdependent functions and mechanisms of regulation. Biofactors. 2009;35:200-8.

35. Vivacqua A, Romeo E, De Marco P, De Francesco EM, Abonante S, Maggiolini M. GPER mediates the Egr-1 expression induced by $17 \beta$-estradiol and 4-hydroxitamoxifen in breast and endometrial cancer cells. Breast Cancer Res Treat. 2012;133:1025-35.

36. Hutchenreuther J, Vincent KM, Carter DE, Postovit LM, Leask A. CCN2 expression by tumor stroma is required for melanoma metastasis. J Invest Dermatol. 2015;135:2805-13.

37. Liu LY, Han YC, WU SH, ZH LV. Expression of connective tissue growth factor in tumor tissues is an independent predictor of poor prognosis in patients with gastric cancer. World J Gastroenterol. 2008;14:2110-4.

38. Bennewith KL, Huang X, Ham CM, Graves EE, Erler JT, Kambham N, et al. The role of tumor cell-derived connective tissue growth factor (CTGF/CCN2) in pancreatic tumor growth. Cancer Res. 2009;69:775-84.

39. Yang F, Tuxhorn JA, Ressler SJ, McAlhany SJ, Dang TD, Rowley DR. Stromal expression of connective tissue growth factor promotes angiogenesis and prostate cancer tumorigenesis. Cancer Res. 2005;65:8887-95.

40. Jia Q, Bu Y, Wang Z, Chen B, Zhang Q, Yu S, et al. Maintenance of stemness is associated with the interaction of LRP6 and heparin-binding protein CCN2 autocrined by hepatocellular carcinoma. J Exp Clin Cancer Res. 2017;36:117

41. Ubink I, Verhaar ER, Kranenburg O, Goldschmeding R. A potential role for CCN2/ CTGF in aggressive colorectal cancer. J Cell Commun Signal. 2016;10:223-7.

42. Kalluri R, Zeisberg M. Fibroblasts in cancer. Nat Rev Cancer. 2006:6:392-401.

43. Gullà A, Di Martino MT, Gallo Cantafio ME, Morelli E, Amodio N, Botta C, et al. A 13 mer LNA-i-miR-221 inhibitor restores drug sensitivity in Melphalan-refractory multiple myeloma cells. Clin Cancer Res. 2016;22:1222-33.
44. Di Martino MT, Gullà A, Gallo Cantafio ME, Altomare E, Amodio N, Leone E, et al. In vitro and in vivo activity of a novel locked nucleic acid (LNA)inhibitor-miR-221 against multiple myeloma cells. PLoS One. 2014;9:e89659.

45. Gallo Cantafio ME, Nielsen BS, Mignogna C, Arbitrio M, Botta C, Frandsen NM, et al. Pharmacokinetics and pharmacodynamics of a 13-mer LNAinhibitor-miR-221 in mice and non-human primates. Mol Ther Nucleic Acids. 2016;5 https://doi.org/10.1038/mtna.2016.36.

46. Franzoni S, Vezzelli A, Turtoro A, Solazzo L, Greco A, Tassone P, et al. Development and validation of a bioanalytical method for quantification of LNA-i-miR-221, a 13-mer oligonucleotide, in rat plasma using LC-MS/MS. J Pharm Biomed Anal. 2018;150:300-7.

47. Chaqour B, Yang R, Sha Q. Mechanical stretch modulates the promoter activity of the profibrotic factor CCN2 through increased actin polymerization and NF-kappaB activation. J Biol Chem. 2006;281:20608-22.

48. Khaled WT, Choon Lee S, Stingl J, Chen X, Raza Ali H, Rueda OM, et al. BCL11A is a triple-negative breast cancer gene with critical function in stem and progenitor cells. Nat Commun. 2015;6:5987.

49. Blows FM, Driver KE, Schmidt MK, Broeks A, van Leeuwen FE, Wesseling J, et al. Subtyping of breast cancer by immunohistochemistry to investigate a relationship between subtype and short and long term survival: a collaborative analysis of data for 10,159 cases from 12 studies. PLoS Med. 2010;7:e1000279.

50. Knoop AS, Laenkholm AV, Jensen MB, Nielsen KV, Andersen J, Nielsen D, et al. Estrogen receptor, progesterone receptor, HER2 status and Ki67 index and responsiveness to adjuvant tamoxifen in postmenopausal high-risk breast cancer patients enrolled in the DBCG 77C trial. Eur J Cancer. 2014;50:1412-21.

51. Maly JJ, Macrae ER. Pertuzumab in combination with Trastuzumab and chemotherapy in the treatment of HER2-positive metastatic breast Cancer: safety, efficacy, and progression free survival. Breast Cancer (Auckl). 2014:8:81-8.

52. Yang Q, Liu HY, Liu D, Song YQ. Ultrasonographic features of triple-negative breast cancer: a comparison with other breast cancer subtypes. Asian Pac J Cancer Prev. 2014;16:3229-32.

53. Iorfida M, Maiorano E, Orvieto E, Maisonneuve P, Bottiglieri L, Rotmensz N, et al. Invasive lobular breast cancer: subtypes and outcome. Breast Cancer Res Treat. 2012;133:713-23.

54. Zhi K, Shen X, Zhang H, Bi J. Cancer-associated fibroblasts are positively correlated with metastatic potential of human gastric cancers. J Exp Clin Cancer Res. 2010;29:66

55. Dong-Le Bourhis X, Berthois Y, Millot G, Degeorges A, Sylvi M, Martin PM, et al. Effect of stromal and epithelial cells derived from normal and tumorous breast tissue on the proliferation of human breast cancer cell lines in coculture. Int J Cancer. 1997;71:42-8.

56. Frazier KS, Grotendorst GR. Expression of connective tissue growth factor mRNA in the fibrous stroma of mammary tumors. Int J Biochem Cell Biol. 1997;29:153-61.

57. Ellis MJ, Singer C, Hornby A, Rasmussen A, Cullen KJ. Insulin-like growth factor mediated stromal-epithelial interactions in human breast cancer. Breast Cancer Res Treat. 1994:31:249-61.

58. Erez N, Truitt M, Olson P, Arron ST, Hanahan D. Cancer-associated fibroblasts are activated in incipient neoplasia to orchestrate tumor-promoting inflammation in an NF-kappaB-dependent manner. Cancer Cell. 2010;17:135-47.

59. Chi Y, Zhou D. MicroRNAs in colorectal carcinoma-from pathogenesis to therapy. J Exp Clin Cancer Res. 2016;35:43.

60. Eissa S, Matboli M, Sharawy A, El-Sharkawi F. Prognostic and biological significance of microRNA-221 in breast cancer. Gene. 2015;574:163-7.

\section{Ready to submit your research? Choose BMC and benefit from:}

- fast, convenient online submission

- thorough peer review by experienced researchers in your field

- rapid publication on acceptance

- support for research data, including large and complex data types

- gold Open Access which fosters wider collaboration and increased citations

- maximum visibility for your research: over $100 \mathrm{M}$ website views per year

At BMC, research is always in progress.

Learn more biomedcentral.com/submissions 